\title{
Composições tecidual e química do lombo de cordeiros alimentados com rações contendo semente de girassol em comedouros privativos ${ }^{1}$
}

\section{Vicente de Paulo Macedo ${ }^{2}$, Cledson Augusto Garcia ${ }^{3}$, Antônio Carlos Silveira ${ }^{4}$, Alda Lúcia Gomes Monteiro ${ }^{5}$, Francisco de Assis Fonseca de Macedo ${ }^{6}$, Rodolfo Cláudio Spers ${ }^{3}$}

\footnotetext{
${ }^{1}$ Projeto financiado pela Universidade de Marília (UNIMAR) e FMVZ, UNESP de Botucatu.

2 ESAPP, Paraguaçu Paulista - SP.

${ }^{3}$ Departamento de Zootecnia - FCA-UNIMAR, CP.504, CEP: 17.525-902, Marília -SP

${ }^{4}$ Departamento de Melhoramento e Nutrição Animal, FMVZ-UNESP, Campus de Botucatu - SP.

${ }^{5}$ Departamento de Zootecnia - UFPR.

${ }^{6}$ Departamento de Zootecnia - UEM, Maringá - PR.
}

RESUMO - O experimento foi realizado objetivando avaliar a composição tecidual e química do músculo Longissimus dorsi de cordeiros Suffolk alimentados em comedouros privativos com ração contendo 0; 6,60; 13,20 ou 19,80\% de semente de girassol. Ao nascer, os cordeiros foram numerados, pesados e distribuídos aleatoriamente nos piquetes compondo quatro repetições por tratamento em um total de 16 cordeiros. As rações continham 2,65; 2,78; 2,89 ou 2,93 Mcal/kg de energia metabolizável e 18,$38 ; 18,75 ; 19,98$ ou $21,18 \%$ de proteína bruta e foram fornecidas à vontade aos cordeiros. Os cordeiros foram pesados a cada 14 dias e mantidos com as ovelhas até atingirem o peso vivo de abate pré-estabelecido (28 kg). As carcaças foram mantidas durante 24 horas na câmara frigorífica a $5^{\circ} \mathrm{C}$ e, posteriormente, foram seccionadas em sete regiões anatômicas para coleta dos lombos esquerdo e direito e obtenção, no músculo Longissimus dorsi, do peso dos componentes do lombo (músculo, osso e gordura) e da composição química e do perfil de ácidos graxos do músculo, do osso e da gordura. A semente de girassol influenciou o peso total do lombo, os pesos de músculo e tecido conjuntivo e o rendimento do tecido conjuntivo. O aumento no percentual de semente de girassol na ração diminuiu a quantidade dos ácidos láurico e palmítico (saturados) e aumentou a dos ácidos oléico e linoléico (insaturados). A qualidade nutricional da carne dos cordeiros melhora com aumento da utilização de semente de girassol na dieta.

Palavras-chave: ácidos graxos, carne, ovinos

\section{Tissue and chemical compositions of loin from lambs fed sunflower seed in creep feeding}

\begin{abstract}
The experiment carried out in aiming to evaluate the tissue and chemical composition of longissimus dorsi muscle of Suffolk lambs fed on creep feeding system with ration containing 0.0, 6.60, 13.20 and 19.80\% of sunflower seed. At kidding, the lambs were identified, weighed and randomly distributed to paddocks composing four replicates per ration, totaling 16 lambs. The rations contained 2.65, 2.78, 2.89 or $2.93 \mathrm{Mcal} / \mathrm{kg}$ of ME and 18.38, 18.75, 19.98 and 21.18\% of CP and were ad libitum fed to the lambs. The lambs were weighed every 14 days and kept with the ewe until they reach the pre-established slaughter body weight $(28 \mathrm{~kg})$. The carcasses were chilling in cold chamber at $5^{\circ} \mathrm{C}$ for 24 hours, and then were split into seven anatomical regions for collection of the left and right loins and obtention of the variables: measures of L. Dorsi muscle, weight of the loin components (muscle, bone and fat); chemical composition and profile of fatty acids of muscle, bone and fat. The sunflower seed influenced total loin weight, muscle and connective tissue weights and connective tissue yield. The increase in sunflower seed percentage in the diet decreased the amount of lauric acid and palmitic (saturated), and increased oleic and linoleic acids (unsaturated). The nutritional quality of meat of lamb improves with increased use of sunflower seed in the diet.
\end{abstract}

Key Words: fatty acids, meat, sheep

\section{Introdução}

O consumo de carne magra tem aumentado em muitos países com a mudança nos hábitos alimentares e a preocupação dos consumidores com a qualidade de vida.
O excesso de gordura, como conseqüência de pesos de abate inadequados, além de afetar a qualidade do produto final, afeta a viabilidade econômica do sistema de produção, como conseqüência da transformação de parte dos nutrientes ingeridos em tecido indesejável. Por sua vez, 
a gordura é desejável para que não haja prejuízos na qualidade da carne, uma vez que evita a desidratação excessiva e as possíveis perdas originadas pelo processo de congelamento (Owen, 1976). Em razão desses fatores, têm-se considerado nos sistemas de classificação de carcaças o grau de gordura como critério de qualidade e preço (Sañudo et al., 2000b) para a carne ovina.

A determinação da proporção de gordura, músculo e osso dos cortes cárneos passaram a ter grande importância nos estudos dos efeitos que influenciam a composição da carcaça. Técnicas foram desenvolvidas para avaliar com precisão esta composição, entre elas, a utilização de ultrasonografia, raios-X e ressonância magnética. Entretanto, normalmente são utilizadas as técnicas de baixo custo, realizadas nas carcaças após o abate, por exemplo, as medidas do músculo Longissimus dorsi, a dissecação de cortes da carcaça e a determinação da composição química por procedimentos laboratoriais (Stanford et al., 1998).

Outro aspecto importante é a qualidade da gordura produzida pelo animal, sobretudo o perfil de ácidos graxos. A partir dos anos 70, a chamada "hipótese lipídica” (Schaefer, 1995) tem correlacionado o consumo de gorduras de origem animal a doenças coronarianas, o que levou à mudança brusca nos hábitos alimentares, refletindo em exigência cada vez maior de produtos de origem animal com baixo teor de colesterol e de gordura, preferencialmente com ácidos graxos insaturados e poliinsaturados.

Vários fatores afetam a composição da carcaça e têm sido estudados na literatura, entre eles, o peso e a idade ao abate, o sexo, a raça e o sistema de produção e alimentação (Sañudo et al., 2000a).

Para antecipar a idade de abate, deve-se explorar a fase de crescimento dos animais. Entre as alternativas adotadas visando à antecipação da idade ao abate, que resulta em aumento da produção de carcaças de cordeiros, tem-se preconizado o uso de comedouros individuais (Garcia et al., 2003a), que representa a suplementação em comedouros individuais durante a fase lactente do cordeiro (Santra \& Karim, 1999). Essa alternativa tem sido freqüentemente utilizada mais por técnicos que atuam na ovinocultura (Pereira \& Santos, 2001; Villas Bôas et al., 2003).

A influência da nutrição do animal nos tecido adiposo e muscular tem sido estudada em cordeiros, tanto na composição em ácidos graxos quanto nos teores de colesterol (Matthes et al., 1996; Yamamoto, 2006). Geay et al. (2001) afirmaram que é possível aumentar a insaturação e reduzir o teor relativo de ácidos graxos saturados e transmonoinsaturados na carne de ruminantes aumentando-se a proporção de ácidos graxos na dieta desses animais.
Assim, o teor de gordura, a composição em ácidos graxos e os níveis de colesterol na carne podem sofrer variações com o uso de sistemas de produção juntamente com o uso de alimentos ricos em ácidos graxos essenciais, como aqueles ricos em ácidos oléico e linoléico (Rowe, 1998).

Entre os alimentos com altos teores de ácido graxos essenciais, o girassol (Helianthus annuus L.) tem sido uma opção para formulação de rações, mostrando-se potencialmente eficiente, por ser rico em proteína e energia (Silva, 1990).

O teor de óleo na semente de girassol varia entre 20 e 40\%, de acordo com o cultivar(Daghir et al., 1980; Karunojeewa et al., 1989), e caracteriza-se pela alta relação de ácidos graxos poliinsaturados/saturados (65,3\%:11,6\%) e os poliinsaturados são constituídos, quase totalmente, pelo ácido linoléico (65\%). Além disso, apresenta aproximadamente 20\% de ácido graxo saturado oléico, também benéfico à saúde humana (Cheva-Isarakul \& Tangtwewipat, 1991).

Este trabalho foi realizado com o objetivo de avaliar a inclusão de semente de girassol na ração de cordeiros sobre a composição tecidual, química e o perfil de ácidos graxos do lombo.

\section{Material e Métodos}

O experimento foi realizado no Setor de Ovinocultura da Fazenda Experimental Marcelo Mesquita Servo, pertencente à Faculdade de Ciências Agrárias da Universidade de Marília (UNIMAR), em Marília, São Paulo. O delineamento experimental foi inteiramente casualizado com quatro tratamentos (níveis de semente de girassol na ração: 0,0; 6,6; 13,2 e $19,8 \%$ ) e quatro repetições. Foram utilizados 16 cordeiros não-castrados, mestiços Suffolk, provenientes de parto simples, alimentados à vontade no período de terminação em comedouros individuais (Tabela 1).

Após o parto, as ovelhas e os cordeiros foram identificados, pesados e distribuídos aleatoriamente em quatro piquetes de estrela-branca (Cynodon plectostachyus), cada um com área de 2,75 ha. Na primeira semana de vida, os cordeiros foram mantidos em área fechada, cercada dos comedouros individuais, por 4 horas diárias (2 horas pela manhã e 2 horas pela tarde) para adaptação às instalações e para o contato inicial com o alimento sólido. As ovelhas receberam diariamente suplementação com ração farelada $(18,50 \%$ PB e $76 \%$ NDT) duas vezes ao dia, em quantidade correspondente a $1 \%$ do peso corporal (PC), com base na matéria seca, para atender os requerimentos nutricionais dessa fase (NRC, 1985). A ração era disponibilizada em comedouro, ao qual somente as ovelhas tinham acesso. 
Tabela 1 - Composição química e nutricional das rações experimentais

\begin{tabular}{lcccc}
\hline Ingrediente $(\mathrm{kg})$ & \multicolumn{5}{c}{ Nível de semente de girassol (\%) } \\
\cline { 2 - 6 } & 0 & 6,6 & 13,2 & 19,8 \\
\hline Nutriente* & & & & \\
\hline Matéria seca (\%) & 91,50 & 91,74 & 91,00 & 90,22 \\
Proteína bruta (\%) & 18,38 & 18,75 & 19,98 & 21,18 \\
Nutrientes digestíveis totais (\%) & 73,35 & 76,87 & 79,85 & 81,02 \\
Energia metabolizável (Mcal/kg) & 2,65 & 2,78 & 2,89 & 2,93 \\
Extrato etéreo (\%) & 3,07 & 6,47 & 10,68 & 13,05 \\
Fibra em detergente neutro (\%) & 22,10 & 22,40 & 24,51 & 24,21 \\
\hline
\end{tabular}

*Análises realizadas no Laboratório de Alimentos da FMVZ - Botucatu. Obs: Inclusão de $300 \mathrm{~g}$ de Rumensin para cada tonelada de ração.

A semente de girassol foi utilizada na forma física quebrada, depois de processada em moinho do tipo faca, sem peneira, em única passagem.

Quando os cordeiros atingiram $28 \mathrm{~kg}$ peso corporal, após 18 horas de jejum de dieta sólida, foram sacrificados. A insensibilização foi feita por eletronarcose com descarga elétrica de $220 \mathrm{~V}$ por 8 segundos e sangria pela secção das veias jugulares e artérias carótidas. Após resfriamento por 24 horas a $5^{\circ} \mathrm{C}$, as carcaças foram seccionadas ao meio e divididas longitudinalmente. Os dois lados foram divididos em sete regiões anatômicas (paleta, perna, lombo, costelas falsas, costelas verdadeiras, baixo e pescoço), segundo Garcia et al. (2003b). Em seguida, foram separados os lombos esquerdo e direito (compreendendo as seis vértebras lombares).

No lombo esquerdo resfriado, entre a última vértebra torácica e a primeira lombar, foram obtidas as seguintes medidas com o uso de paquímetro (Garcia et al. 2003b): medida $\mathrm{A}$ = largura máxima do músculo; medida $\mathrm{B}$ = profundidade máxima do músculo; medida $\mathrm{C}$ = menor espessura de gordura sobre o músculo; medida $\mathrm{J}$ = maior espessura de gordura de cobertura no perfil do lombo. Para determinação da área de olho-de-lombo, foi colocada uma folha de papel transparente sobre a área transversal do músculo, entre a última vértebra torácica e a primeira lombar, e desenhado o contorno do músculo, o que possibilitou a obtenção da área de olho-de-lombo com o uso do planímetro.

O lombo esquerdo foi congelado e, no dia da dissecação, retirado do congelador e mantido à temperatura ambiente por aproximadamente 2 horas. Os lombos foram dissecados e os tecidos ósseo, muscular, adiposo (gorduras subcutânea e intermuscular) e conjuntivo foram separados e pesados em balança eletrônica de precisão de $1 \mathrm{~g}$.

Amostras foram coletadas do músculo Longissimus dorsi, do lombo, referente ao lado direito da carcaça, sem a porção de gordura de cobertura localizada nesta região, para análises dos teores de umidade, cinzas, proteína e extrato etéreo (gordura intramuscular) (AOAC, 1990).

A análise da composição em ácidos graxos foi realizada por meio de cromatografia gás-líquido e os ésteres de ácidos graxos analisados em cromatógrafo Shimadzu, com coluna capilar de sílica fundida (Folch et al., 1957; Hartman \& Lago, 1973), no Laboratório de Tecnologia de Alimentos de Maringá.

A análise estatística para estudo das variáveis foi realizada por análise de variância utilizando-se o Sistema de Análises Estatísticas e Genéticas (SAEG - UFV, 1997) de acordo com o seguinte modelo:

$$
\mathrm{Yij}=\mu+\mathrm{Ni}+\mathrm{eij}
$$

em que: $\mathrm{Yij}=$ valor observado da variável estudada no indivíduo j recebendo o nível de semente de girassol i; $\mu$ = constante geral; $\mathrm{Ni}=$ efeito do nível de semente de girassol na ração i, i = 0,0; 6,6; 13,2 e 19,8; e eij = erro aleatório associado a cada observação Yij.

Os resultados significativos $(\mathrm{P}=0,05)$ foram submetidos à análise de regressão polinomial.

\section{Resultados e Discussão}

Os níveis de semente de girassol na ração não influenciaram $(\mathrm{P}>0,05)$ as medidas do músculo Longissimus dorsi (Tabela 2), resultado próximo aos observados por Neres (2000 et al., 2001 b) e Garcia et al. (2003 b) em experimento com cordeiros Suffolk abatidos com $28 \mathrm{~kg}$ peso corporal alimentados em comedouro individual.

Stanford et al. (1998) relataram que as medidas realizadas no músculo Longissimus dorsi para avaliação das carcaças de cordeiros são feitas desde 1939. Embora não sejam muito precisas para serem consideradas como estimativa da composição da carcaça, são ainda muito utilizadas pela facilidade de obtenção e pelo custo reduzido. Entretanto, Macedo (1998) e Bueno et al. (2000) citaram que a área do olho-de-lombo é considerada medida objetiva de grande valor na predição da quantidade de músculo na carcaça, enquanto a avaliação da gordura é fundamental, uma vez que pode ser fator determinante de sua qualidade. Salienta-se que este músculo é importante por fazer parte do conjunto de cortes de elevado valor comercial; portanto, quanto maior a área do olho-de-lombo, mais valorizada será a carcaça (Siqueira \& Fernandes, 2000).

Fatores como nutrição, sexo, genótipo, idade e peso ao abate podem ter afetado as medidas do Longissimus dorsi avaliadas neste trabalho. O peso ao abate é um dos principais fatores que afetam a área de olho-de-lombo, como 
Tabela 2 - Características do músculo Longissimus dorsi de cordeiros alimentados com rações contendo semente de girassol

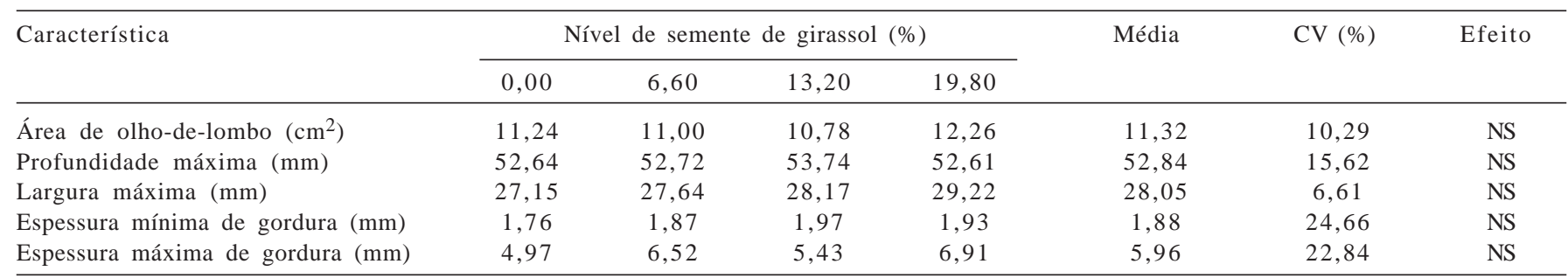

NS = não-significativo $(P>0,05)$.

constatado nos trabalhos de Silva \& Pires (2000) e Bueno et al. (2000), nos quais cordeiros abatidos mais pesados apresentaram maior área de olho-de-lombo. Quando os cordeiros foram abatidos com pesos próximos aos deste estudo, como nos trabalhos de Neres et al. (2001 a), Siqueira \& Fernandes (2000) e Carvalho (2002), não foram observadas diferenças na área do olho-de-lombo, mesmo quando utilizadas diferentes dietas.

Os resultados referentes à área do olho-de-lombo foram próximos aos obtidos por Neres et al. (2001b), 11,55 $\mathrm{cm}^{2}$, Siqueira \& Fernandes (2000), 9,44 $\mathrm{cm}^{2}$, e Reis et al. (2001), $12,60 \mathrm{~cm}^{2}$, uma vez que o peso vivo ao abate dos cordeiros foi também semelhante.

Do mesmo modo, não foi possível observar efeito $(\mathrm{P}>0,05)$ dos níveis de semente de girassol, mesmo com o aumento no extrato etéreo de 3 a 13\% da MS (Tabela 1) nas dietas sobre as medidas de espessura da gordura subcutânea sobre o Longissimus dorsi. A gordura subcutânea tem grande importância nas carcaças ovinas e consiste em fator determinante nos sistemas de classificação de carcaças (Yamamoto, 2006).

Não houve efeito $(\mathrm{P}>0,05)$ dos níveis de semente de girassol na ração sobre os pesos das gorduras subcutânea e intermuscular (Tabela 3), o que está de acordo com os resultados observados de espessuras mínima e máxima de gordura. Monteiro et al. (2002) encontraram pesos de gordura subcutânea e intermuscular iguais a 39,10 e 39,36 g, respectivamente, em pesquisa com cordeiros Suffolk abatidos com $28 \mathrm{~kg}$ PC, disponibilizando dietas isoprotéicas (21\% PB) e isoenergéticas (3,0 Mcal EM/kg MS) em comedouro privativo. Sá (2001) também obteve pesos iguais a 38,76 e 22,19 g para as respectivas gorduras, utilizando cordeiros Hampshire Down abatidos com PC próximos aos $30 \mathrm{~kg}$. Siqueira \& Fernandes (2000), no entanto, trabalhando com cordeiros de raça lanígera Corriedale e mestiços Ile de France $\times$ Corriedale abatidos com 30 a $32 \mathrm{~kg}$, verificaram pesos de 12,7 g para gordura subcutânea e 5,8 g para intermuscular, provavelmente em razão da característica da raça. Os resultados encontrados neste experimento para a gordura subcutânea foram bastante superiores aos obtidos por esses pesquisadores.

Os valores médios de gordura subcutânea encontrados neste estudo devem ser vistos com cautela, pois são semelhantes aos de gordura total do lombo obtidos por Siqueira et al. (2001) e Oliveira et al. (2002) em cordeiros abatidos com 28 e $45 \mathrm{~kg}$ de peso corporal, respectivamente.

Harrington \& Kempster (1989), citados por Neto (1997), sugeriram que a gordura intermuscular deve ser reduzida na carne, fato que traria significativa melhora na qualidade, do ponto de vista nutracêutico. Neste trabalho, a quantidade de gordura intermuscular estava em quantidades aceitáveis.

Então, a inclusão de fonte lipídica na dieta pela semente de girassol não afetou os componentes teciduais nas variáveis peso e rendimento de gorduras (Tabela 4), assim como observado para as medidas de espessura mínima e máxima de gordura.

Os pesos de lombo, de tecido muscular e tecido conjuntivo tiveram efeito quadrático $(\mathrm{P}<0,05)$ dos níveis de semente de girassol na ração (Tabela 4 ). O valor médio para peso total do lombo deste experimento foi intermediário aos valores obtidos por Sá (2001), 615,35 g, e Monteiro et al. (2002), 679,73 g. O mesmo ocorreu para o peso do tecido conjuntivo. Os valores obtidos para peso de músculo também foram próximos, embora superiores aos descritos por esses autores (398,41 e 393,29 g, respectivamente), que abateram os cordeiros com peso final semelhante (28-29 kg), comprovando a relação entre peso de tecido muscular e peso corporal dos animais.

Entre os rendimentos dos componentes teciduais, somente a porcentagem de tecido conjuntivo foi influenciada $(\mathrm{P}<0,05)$ pelos níveis de semente de girassol, o mesmo comportamento quadrático do peso do tecido conjuntivo.

O resultado do valor médio para rendimento de músculo foi inferior aos obtidos por Preziuso et al. (1999), Siqueira et al. (2001) e Priolo et al. (2002), que encontraram 57,08; 59,59 e 59,07\%. O valor médio para o rendimento do osso foi próximo aos obtidos por esses pesquisadores: 20,80; 18,12 
Tabela 3 - Peso do lombo (g) e pesos e rendimentos (\%) de músculo, osso, tecido conjuntivo, gordura subcutânea e gordura intermuscular de cordeiros alimentados com rações contendo semente de girassol

\begin{tabular}{|c|c|c|c|c|c|c|c|}
\hline Peso (g) & \multicolumn{4}{|c|}{ Nível de semente de girassol (\%) } & Média & CV (\%) & Efeito \\
\hline Lombo & 659,21 & 587,11 & 625,17 & 667,54 & 635,75 & 8,70 & 1 \\
\hline Osso & 118,12 & 106,57 & 131,94 & 118,50 & 118,78 & 19,31 & 2 \\
\hline Tecido conjuntivo & 47,25 & 33,28 & 37,14 & 40,09 & 39,44 & 20,41 & 3 \\
\hline Gordura subcutânea & 102,23 & 91,54 & 76,29 & 99,48 & 92,38 & 29,44 & NS \\
\hline Lombo & 54,14 & 55,16 & 55,30 & 55,11 & 54,93 & 6,21 & NS \\
\hline Músculo & 18,20 & 18,13 & 21,07 & 17,92 & 18,83 & 19,57 & NS \\
\hline Osso & 7,11 & 5,60 & 5,89 & 6,15 & 6,19 & 18,29 & 1 \\
\hline Tecido conjuntivo & 15,18 & 14,86 & 12,03 & 14,80 & 14,22 & 22,61 & NS \\
\hline Gordura subcutânea & 4,06 & 5,09 & 4,29 & 4,60 & 4,50 & 29,72 & NS \\
\hline
\end{tabular}

1 - Efeito quadrático $(P<0,05) ; 2$ - Efeito cúbico $(P<0,05)$; NS = não-significativo $(P>0,05)$.

Tabela 4 - Equação de regressão e coeficiente de determinação $\left(R^{2}\right)$ para pesos $(\mathrm{g})$ de lombo, músculo e osso e para peso e rendimento do tecido conjuntivo de cordeiros alimentados com rações contendo semente de girassol

\begin{tabular}{lll}
\hline Variável & \multicolumn{1}{c}{ Equação } & $\mathrm{R}^{2}$ \\
\hline Peso do lombo (g) & $\hat{\mathrm{Y}}=597,9139-6,2441 \mathrm{X}+29,6688 \mathrm{X}^{2}$ & 0,96 \\
Peso do músculo (g) & $\hat{\mathrm{Y}}=327,5959-6,5798 \mathrm{X}+15,8264 \mathrm{X}^{2}$ & 0,85 \\
Peso do osso (g) & $\hat{\mathrm{Y}}=118,9550+28,2208 \mathrm{X}-0,3824 \mathrm{X}^{2}-12,5635 \mathrm{X}^{3}$ & 1,00 \\
Tecido conjuntivo (g) & $\hat{\mathrm{Y}}=34,0885-1,6048 \mathrm{X}+4,4248 \mathrm{X}^{2}$ & 0,85 \\
Tecido conjuntivo (\%) & $\hat{\mathrm{Y}}=5,6117-0,2599 \mathrm{X}+0,4647 \mathrm{X}^{2}$ & 0,86 \\
\hline
\end{tabular}

Tabela 5 - Composição química do músculo Longissimus dorsi de cordeiros alimentados com rações contendo semente de girassol

\begin{tabular}{|c|c|c|c|c|c|c|c|}
\hline \multirow[t]{2}{*}{ Variável } & \multicolumn{4}{|c|}{ Nível de semente de girassol (\%) } & \multirow[t]{2}{*}{ Média } & \multirow[t]{2}{*}{ CV (\%) } & \multirow[t]{2}{*}{ Efeito } \\
\hline & 0,00 & 6,60 & 13,20 & 19,80 & & & \\
\hline Umidade (\%) & 74,48 & 74,61 & 75,25 & 74,40 & 74,69 & 1,29 & NS \\
\hline Cinzas (\%) & 1,09 & 1,08 & 1,08 & 1,09 & 1,08 & 4,02 & NS \\
\hline Extrato etéreo (\%) & 2,19 & 3,04 & 2,74 & 2,76 & 2,68 & 15,02 & NS \\
\hline Proteína (\%) & 21,92 & 20,82 & 20,19 & 21,15 & 21,02 & 5,56 & NS \\
\hline
\end{tabular}

NS = não-significativo $(P>0,05)$.

e $20,80 \%$. Os cordeiros utilizados nesses trabalhos, no entanto, foram terminados em confinamento e abatidos com 28; 31 e 35 kg PC, respectivamente.

Preziuso et al. (1999) e Velasco et al. (2001) encontraram rendimentos médios de gordura subcutânea de 9,30 e 7,10\% e de gordura intermuscular de 4,80 e 3,35\%. Velasco et al. (2001) abateram os cordeiros com $14 \mathrm{~kg}$ peso corporal, portanto, confirma-se mais a relação entre peso de abate e composição em gordura (Siqueira \& Fernandes, 2000).

A composição química do músculo Longissimus dorsi não foi influenciada $(\mathrm{P}>0,05)$ pelos níveis de semente de girassol na ração dos cordeiros.

De acordo com Prata (2001), a composição centesimal da carne ovina apresenta valores médios de 75\% de umidade,
19\% de proteína, 4\% de gordura e 1\% de matéria mineral. A análise da composição química comprovouvalores bem próximos aos citados e permitiu conhecer o valor nutritivo da carne que pode ser influenciado, além da dieta, por outros fatores, principalmente peso e idade ao abate. Esta constatação pode ser verificada nos trabalhos de Silva et al. (1999) e Prado et al. (1999), em que os teores de umidade diminuíram e os de proteína e extrato etéreo aumentaram com o aumento do peso e idade ao abate. Ressalta-se que os teores de lipídeos da carne de cordeiros variam de acordo com a raça, o sexo e o músculo estudado (Yamamoto, 2006), o que deve estar claro na metodologia dos trabalhos.

Neste caso, a carne dos cordeiros apresentou 21\% de proteína bruta e 2,68\% de extrato etéreo, valores pouco 
inferiores aos obtidos por Yamamoto (2006) com cordeiros Ile de France $\times$ Ideal abatidos aos 32 kg (25,66\% PB; extrato etéreo $3,48 \%$ ).

Como neste experimento, os cordeiros foram abatidos com aproximadamente 60 dias de idade (59, 68, 62 e 59 dias, conforme inclusão de semente de girassol) e peso corpral em torno de $28-29 \mathrm{~kg}(29,01 ; 28,09 ; 28,38$ e 28,53 kg), os resultados de umidade, estrato etéreo e proteína são indicativos de carne com boa qualidade, inclusive com gordura intramuscular desejável, de boa aceitabilidade pelo consumidor.

Ainda que não interfira no sabor, o teor de gordura pode correlacionar-se a componentes adipócitos, na forma de gordura intramuscular, inclusive ocorrendo variação na composição dos ácidos graxos saturados e insaturados, em razão da manipulação da dieta, que influencia mais que a genética (Lopez-Franco, 1991).

Não houve efeito $(\mathrm{P}>0,05)$ dos níveis de semente de girassol na ração sobre o percentual dos ácidos graxos mirístico(C14:0), heptadecanóico(C17:1) e esteárico (C18:0) (Tabela 6).

Os teores de ácidos graxos palmítico (C16:0), oléico (C18:1) e linoléico (C18:2) responderam de forma linear $(\mathrm{P}<0,05)$ aos níveis de semente de girassol; verificou-se comportamento linear decrescente para ácido graxo palmítico (C16:0) e crescente para ácidos graxos oléico (C18:1) e linoléico (C18:2) (Tabela 7).

Segundo Monteiro (1997), os ácidos graxos saturados mais encontrados na carne ovina são o mirístico, palmítico e esteárico; os monoinsaturados são o palmitoléico e oléico; e os poliinsaturados são o linoléico, linolênico e araquidônico. No entanto, é possível aumentar o grau de insaturação na carne dos ruminantes, aumentando a proporção de ácidos graxos poliinsaturados na dieta dos animais (Geay et al., 2001).
As respostas obtidas para os ácidos graxos (Tabela 7) confirmam a afirmativa de que a concentração do ácido graxo palmítico (C16:0) no farelo de soja é menor que a da semente de girassol, do mesmo modo que as concentrações dos ácidos graxos oléico (C18:1) e linoléico (C18:2) na semente de girassol são maiores que no farelo de soja. Ressalta-se que a porcentagem de farelo de soja diminuiu com o aumento dos níveis de semente de girassol nas dietas experimentais.

Os ácidos graxos oléico (C18:1) palmítico (C16:0) e linoléico (C18:0) foram, respectivamente, os encontrados em maiores concentrações nas amostras do músculo Longissimus dorsi, perfazendo aproximadamente $80 \%$ dos ácidos graxos identificados. Estes resultados estão de acordo com os relatados por Enser et al. (1996), que, em amostras do músculo Longissimus dorsi de cordeiros, encontraram o ácido graxo oléico (C18:1) como principal ácido graxo insaturado, tendo o ácido graxo palmítico (C16:0) foi encontrado em maior concentração que o ácido graxo esteárico (C18:0). Outros ruminantes, como os bovinos e caprinos apresentam praticamente o mesmo perfil dos ovinos. Os ácidos graxos oléico (C18:1), palmítico (C:16:0) e esteárico (C18:0) (Park \& Washington 1993; Enser et al., 1996).

Bett (2002), utilizando grãos de girassol na ração de vacas leiteiras observou menor concentração de ácido graxo palmítico (C16:0) (23,36\%) no leite dos animais que recebiam a dieta com esta oleaginosa, em comparação à dieta sem girassol (26,81\%). Garcia et al. (2002), no entanto, obtiveram para ácido graxo palmítico (C16:0) concentração de 47,26\%. A redução na concentração do ácido graxo palmítico (C16:0) no músculo Longissimus dorsi de cordeiros não foi observado por Solomon et al. (1991), quando utilizaram dietas contendo semente de canola integral e farelo de soja.

Tabela 6 - Composição percentual de ácidos graxos (\%) do músculo Longissimus dorsi de cordeiros alimentados com rações contendo semente de girassol

\begin{tabular}{|c|c|c|c|c|c|c|c|}
\hline Ácido graxo & \multicolumn{4}{|c|}{ Nível de semente de girassol (\%) } & Média & $\mathrm{CV}(\%)$ & Efeito \\
\hline Laúrico (C12:0) & 0,36 & 0,38 & 0,46 & 0,41 & 0,40 & 10,20 & 2 \\
\hline Palmítico (C16:0) & 24,21 & 23,02 & 23,30 & 20,76 & 22,82 & 5,02 & 1 \\
\hline Heptadecanóico (C17:1) & 1,02 & 1,15 & 0s,97 & 0,97 & 1,03 & 18,15 & NS \\
\hline Esteárico (C18:0) & 14,14 & 15,46 & 15,47 & 15,39 & 15,12 & 8,87 & NS \\
\hline Saturados* & 42,91 & 43,10 & 43,65 & 40,44 & 42,53 & 2,87 & 1 \\
\hline Insaturados* & 54,76 & 57,65 & 58,48 & 59,87 & 57,69 & 2,60 & 1 \\
\hline
\end{tabular}

* Total de ácidos graxos saturados e insaturados identificados nas amostras.

NS= não-significativo $(P>0,05) ; 1$ - Efeito linear $(P<0,05) ; 2$ - Efeito cúbico $(P<0,05)$. 
Tabela 7 - Equações de regressão e coeficiente de determinação $\left(\mathrm{R}^{2}\right)$ dos ácidos graxos do músculo Longissimus dorsi de cordeiros alimentados com rações contendo semente de girassol

\begin{tabular}{lcc}
\hline Ácido graxo & Equação & $\mathrm{R}^{2}$ \\
\hline Láurico (C12:0) & $\hat{\mathrm{Y}}=0,4255+0,0841 \mathrm{X}-0,0151 \mathrm{X} 2-0,0290 \mathrm{X}^{3}$ & 1,00 \\
Palmítico (C16:0) & $\hat{\mathrm{Y}}=22,8258-1,0010 \mathrm{X}$ & 0,84 \\
Oléico (C18:1) & $\hat{\mathrm{Y}}=44,0407+1,1307 \mathrm{X}$ & 0,80 \\
Linoléico (C18:2) & $\hat{\mathrm{Y}}=12,6141+0,5171 \mathrm{X}$ & 0,80 \\
Saturados & $\hat{\mathrm{Y}}=42,5300-0,6808 \mathrm{X}$ & 0,60 \\
Insaturados & $\hat{\mathrm{Y}}=57,6958+1,1614 \mathrm{X}$ & 0,80 \\
\hline
\end{tabular}

Muci et al. (1992) adicionaram 5\% de óleo de girassol em dieta controle e observaram aumento significativo nas concentrações dos ácidos graxos oléico (C18:1) e linoléico (C18:2) em amostras do músculo Longissimus dorsi de cordeiros e ainda observaram redução no teor de colesterol da carne. Bett (1999) obtiveram valores para ácidos graxos oléico (C18:1) e linoléico(C18:2) de 39,42 e 2,78, respectivamente. Os valores obtidos neste experimento apresentaram maior diferença para o ácido graxo linoléico (C18:2), o que pode estar relacionado à menor concentração de ácido graxo linoléico (C18:2) na semente de canola em comparação a semente de girassol, confirmando que a dieta tem papel importante sobre a alteração do perfil de ácidos graxos no produto final de ruminantes.

Os ácidos graxos monoinsaturados, como o ácido oléico, têm poder redutor de colesterol e lipoproteína de baixa densidade (LDL). O ácido graxo poliinsaturado linoléico, no entanto, é considerado essencial, uma vez que não pode ser sintetizado pelos animais (Lehninger, 1990) e deve ser fornecido na dieta. Assim, são ácidos graxos de muita importância para a saúde humana. Neste trabalho, as concentrações de ácido oléico e linoléico aumentaram de forma crescente (Tabela 7) aos níveis de semente de girassol na dieta, melhorando a qualidade da carne.

O ácido graxo saturado laúrico (C12:0), além de ser encontrado em menor concentração, respondeu com equação polinomial cúbica $(\mathrm{P}<0,05)$ aos níveis de semente de girassol, impossibilitando a discussão deste resultado.

No somatório dos ácidos graxos saturados e insaturados, houve efeito linear $(\mathrm{P}<0,05)$ decrescente e crescente, respectivamente (Tabela 7), respostas condizentes às encontradas para os ácidos graxos palmítico (C16:0), oléico (C18:1) e linoléico (C18:2), uma vez que foram encontrados em maiores concentrações, influenciando diretamente no total dos ácidos graxos saturados e insaturados.

As médias para as concentrações totais dos ácidos graxos insaturados foram superiores às dos ácidos graxos saturados, resultado importante do ponto de vista nutricional, pois promovem benefícios à saúde (Andrade, 1994). De acordo com Wood et al. (2003), a relação entre ácidos graxos poliinsaturados:ácidos graxos saturados (AGP:AGS) para uma dieta saudável deve ser superior a 0,4. Considerando apenas o ácido poliinsaturado linoléico e os ácidos graxos saturados identificados na análise do Longissimus dorsi (Tabela 6), obteve-se relação de 0,27 a 0,32 com o aumento do nível de semente de girassol. Em muitas carnes de ruminantes, essa relação tem sido próxima de 0,1 (Wood et al., 2003).

\section{Conclusões}

Em cordeiros, o tecido muscular é o componente tecidual do lombo mais influenciado pelo fornecimento de semente de girassol na ração, uma vez que apresenta maiores pesos e rendimentos nos maiores níveis de semente de girassol. A semente de girassol altera o perfil de ácidos graxos do músculo Longissimus dorsi, ocasinando diminuição do ácido graxo saturado palmítico e aumento da insaturação da carne pelos ácidos graxos oléico e linoléico, o que melhora a qualidade da carne para consumo.

\section{Literatura Citada}

ANDRADE, A.D. Ácidos graxos ômega-3 em peixes, óleos de peixes vegetais comestíveis. Maringá: Universidade Estadual de Maringá, 1994. 67p. Dissertação (Mestrado em Química) Universidade Estadual de Maringá, 1994.

ASSOCIATION OF OFFICIAL ANALYTICAL CHEMISTS - AOAC. Official methods of analysis. 15.ed. Arlington: 1990. 1298p. BETT, V. Utilização do grão de canola na alimentação de cordeiros em terminação. Maringá: Universidade Estadual de Maringá, 1999. 38p. Dissertação (Mestrado em Zootecnia) Universidade Estadual de Maringá, 1999.

BETT, V. Grãos de girassol em rações para vacas leiteiras. Jaboticabal: Universidade Estadual Paulista, 2002. 115p. Tese (Doutorado em Zootecnia) - Universidade Estadual Paulista, 2002.

BUENO, M.S.; CUNHA, E.A.; SANTOS, L.E. et al. Características de carcaça de cordeiros Suffolk abatidos em diferentes idades. Revista Brasileira de Zootecnia, v.29, n.6, p.1803-1810, 2000 . 
CARVALHO, S.R.S. Desempenho e caracteres corporais de cordeiros inteiros e castrados, submetidos a dois fotoperíodos. Botucatu: Universidade Estadual Paulista, 2002. 75p. Dissertação (Mestrado em Zootecnia) - Universidade Estadual Paulista, 2002.

CHEVA-ISARAKUL, B.; TANGATAWEEWIPAT, S. Effect of different levels of sunflower seed in broiler rations. Poultry Science, n.70, p.2284-2294, 1991.

DAGHIR, N.J.; RAZ, M.A.; UWAYJAN, M. Studies the utilization of full fat sunflower seed in broiler rations. Poultry Science, n.59, p.2273-2278, 1980.

ENSER, M.; HALLETT, K.; HEWWITT, B. et al. Fatty acid content and composition of english beef, lamb and pork at retail. Meat Science, v.42, n.4, p.443-456, 1996.

FOLCH, J.; LEE, M.; SLOANE STANLEY, G.H. A simples method for isolation and purification of total lipids from animal tissue. Journal Biological Chemistry, v.226, p.497-509, 1957.

GARCIA, C.A.; COSTA, C.; MONTEIRO, A.L.G. et al. Níveis de energia no desempenho e características da carcaça de cordeiros alimentados em creep feeding. Revista Brasileira de Zootecnia, v.32, n.6, 1371-1379, 2003a.

GARCIA, C.A.; MONTEIRO, A.L.G.; COSTA, C. et al. Medidas objetivas e composição tecidual da carcaça de cordeiros alimentados com diferentes níveis de energia em creep feeding. Revista Brasileira de Zootecnia, v.32, n.6, p.1380-1390, 2003b.

GARCIA, C.A.; MONTEIRO, A.L.G.; COSTA, C. et al. Composição dos ácidos do músculo Longissimus dorsi de cordeiros alimentados com diferentes níveis de energia em sistema de creep feeding. In: REUNIÃO DA SOCIEDADE BRASILEIRA DE ZOOTECNIA, 39., 2002, Recife. Anais... Recife: Sociedade Brasileira de Zootecnia/Gmosis, [2002] 17 par. (CD-ROM).

GEAY, Y.; BAUCHART, D.; HOCQUETTE, J.F. et al. Effect of nutritional factors on biochemical, structural and metabolic characteristics of muscles in ruminants, consequences on diet value and sensorial qualities of meat. Reproduction Nutrition Development, v.41, p.1-26, 2001.

HARTMAN, L.; LAGO, B.C.A.A. Rapid prepationof fastty, methyl esters from lipids. Laboratory Practical, v.22, p.457-477, 1973.

KARUNOJEEWA, H.; THAN, S.H.; ABU-SEREWA, S. Sunflower seed meal, sunflower oil and full-fat sunflower seeds, hulls and kernels for laying hens. Animal Feed Science Technology, n.26, p.45-54, 1989

LEHNINGER, A.L. Princípios de bioquímica. Traduzido por LODI, W.R.; SIMÕES, A.A. São Paulo: Savier, 1990. $723 p$.

LOPEZ-FRANCO, L. La calidad de la carne de ovino en España. Mundo Ganadero, v.4, p.46-54, 1991

MACEDO, F.A.F. Desempenho e características de carcaças de cordeiros Corriedale mestiços Bergamácia x Corriedale e Hampshire Down x Corriedale, terminados em pastagem e confinamento. Botucatu: Universidade Estadual Paulista, 1998. 72p. Tese (Doutorado em Zootecnia) - Universidade Estadual Paulista, 1998.

MATTHES, H.D.; NÜRNEERG, K.; MÖHRING, H. et al. Fettäurenzusammensetzyng von lammfleisch in abhängigkeit von der fütterung. Fleischwirtschaft, v.76, n.9, p.907-909, 1996.

MONTEIRO, A.L.G.; ALMEIDA JR., G.A.; GARCIA, C.A. et al. Características quantitativas e qualitativas do músculo Longissimus dorsi de cordeiros alimentados com silagem de grãos úmidos de milho em sistema de "creep feeding". In: REUNIÃO DA SOCIEDADE BRASILEIRA DE ZOOTECNIA, 39., 2002, Recife. Anais... Recife: Sociedade Brasileira de Zootecnia/Gmosis, [2002] 17 par. (CD-ROM).

MONTEIRO, E.M. Influência do cruzamento Ile de France $\mathbf{x}$ Corriedale (F1) nos parâmetros de qualidade de carne de cordeiros. São Paulo: Universidade Estadual Paulista, 1998. 99p. Tese (Doutorado em Ciência dos Alimentos) - Universidade Estadual Paulista, 1998.
MUCI, M.R.; CAPPELLO, A.R.; VONGHIA, G. et al. Change in cholesterol levels and in lipid fatty acid composition in sunflower oil fed lambs. International Journal for Vitamin and Nutrition Research, n.62, p.330-333, 1992.

NATIONAL RESEARCH COUNCIL - NRC. Nutrient requirements of sheep. Washington, D.C.: National Academy Press, 1985. 99p.

NERES, M.A.; GARCIA, C.A.; MONTEIRO, A.L.G. et al. Níveis de feno de alfafa e forma física da ração no desempenho de cordeiros em "creep feeding". Revista Brasileira de Zootecnia, v.30, n.3, 941-947, 2001a (supl. 1).

NERES, M.A.; MONTEIRO, A.L.G.; GARCIA, C.A. et al. Forma física da ração e pesos de abate nas características de carcaça de cordeiros em "creep feeding". Revista Brasileira de Zootecnia, v.30, n.3, p.941-947, 2001b (supl. 1).

NETO, M.J.L. Caracteres qualitativos da carne de cordeiros da raça Corriedale e mestiços Ile de France $x$ Corriedale, terminados em confinamento. Botucatu: Universidade Estadual Paulista, 1997. 33p. Dissertação (Mestrado em Zootecnia) - Universidade Estadual Paulista, 1997.

OLIVEIRA, M.N.M.; PÉREZ, J.R.O.; ALVES, E.L. et al. Avaliação da composição de cortes comerciais, componentes corporais e órgãos internos de cordeiros confinados e alimentados com dejetos de suínos. Revista Brasileira de Zootecnia, v.31, n.3, p.1459-1468, 2002 (supl.).

OWEN, J.B. Sheep production. 4.ed. London: Bailliére Tindall, 1976. 436p.

PARK, Y.W.; WASHINGTON, A.C. Fatty acid composition of goat organ and muscle meat of Alpine and Nubian breeds. Journal of Food Science, v.58, n.2, p.245-253, 1993.

PEREIRA, J.R.A.; SANTOS, I.C. Produção de ovinos: sistema intensivo para produção de carne ovina. Ponta Grossa: Universidade Estadual de Ponta Grossa, 2001. p.7-19.

PRADO, O.V.; PÉREZ, J.R.O.; BRESSAN, M.C. et al. Composição centesimal do músculo Longissimus dorsi de cordeiros das raças Santa Inês e Begamácia criados em confinamento e abatidos em diferentes pesos. In: REUNIÃO ANUAL, DA SOCIEDADE BRASILEIRA DE ZOOTECNIA, 36., 1999, Porto Alegre. Anais... Rio Grande do Sul:Sociedade Brasileira de Zootecnia, 1999. p.348.

PRATA, L.F.; FUKUDA, R.T. Fundamentos da higiene e inspeção de carnes. Jaboticabal: FUNEP, 2001. 349p.

PREZIUSO, G.; RUSSO, C.; CASAROSA, G. et al. Effect of diet energy source on weight gain and carcass characteristics of lambs. Small Ruminant Research, v.33, p.9-15, 1999.

PRIOLO, A.; MICIOL, D.; AGABRIEL, J. et al. Effect of grass on concentrate feeding sytems on lamb carcass and meat quality. Meat Science, v.62, p.179-185, 2002.

REIS, W.; JOBIM, C.G.; MACEDO, F.AF. et al. Características de cordeiros alimentados com dietas contendo grãos de milho conservados em diferentes formas. Revista Brasileira de Zootecnia, v.30, n.4, p.1308-1315, 2001.

ROWE, A. Composição muscular e ácidos graxos em ovinos de diferentes grupos genéticos submetidos a dois sistemas de terminação. Maringá: Universidade Estadual de Maringá, 1998. 102p. Dissertação (Mestrado em Química) - Universidade Estadual de Maringá, 1998.

SÁ, J.L. Efeito de dois fotoperíodos sobre o desempenho, níveis hormonais e caracteres da carcaça e da carne de cordeiros machos das raças Hampshire Down e Santa Inês, terminados em confinamento. Botucatu: Universidade Estadual de Maringá, 2001. 106p. Tese (Doutorado em Zootecnia) - Universidade Estadual Paulista, 2001.

UNIVERSIDADE FEDERAL DE VIÇOSA - UFV. 1997. SAEG Sistema de análises estatísticas e genéticas. Viçosa, MG: 1997. 150p. (Manual do usuário).

SANTRA, A.; KARIM, S.A. Effects of protein levels in creep mixture on nutrient utilization and growth performance of preweaner lambs. Small Ruminant Research, v.33, p.131-136, 1999. 
SAÑUDO, C.; ENSER, M.E.; CAMPO, M.M. et al. Fatty acid composition and sensory characteristics of lamb carcasses from Britain and Spain. Meat Science, v.54, p.339-346, 2000a.

SAÑUDO, C.; ALFONSO, M.; SANCHEZ, A. et al. Carcass and meat quality in light lambs from different fat classes in the EU carcass classification system. Meat Science, v.56, p.89-94, 2000b.

SCHAEFER, A.L. New techniques to reduce fatness in farm animals. In: JONES S.D.M. (Ed.) Quality and grazing of carcass of meat animals. Boca Raton: CRC Press, 1995. 593p.

SILVA, M.N. A cultura do girassol. Jaboticabal: FUNEP, 1990. $67 p$.

SILVA, R.F.; PIRES, C.C.; SANCHEZ, L.M.B. et al. Conteúdo corporal em proteína, gordura, energia e matéria mineral de cordeiros em crescimento. In: REUNIÃO ANUAL, DA SOCIEDADE BRASILEIRA DE ZOOTECNIA, 36., 1999, Porto Alegre. Anais... Rio Grande do Sul: Sociedade Brasileira de Zootecnia, 1999. p.255.

SILVA, R.F.; PIRES, C.C. Avaliações quantitativas e predição das proporções de osso, músculo e gordura da carcaça em ovinos. Revista Brasileira de Zootecnia, v.29, n.4, p.1253-1260, 2000.

SIQUEIRA, E.R.; FERNANDES, S. Efeito do genótipo sobre as medidas objetivas e subjetivas da carcaça de cordeiros terminados em confinamento. Revista Brasileira de Zootecnia, v.29, n.1, p.306-311, 2000.
SIQUEIRA, E.R.; SIMÕES, C.D.; FERNANDES, S. Efeito do sexo e do peso ao abate sobre a produção de carne de cordeiro. 1. Velocidade de crescimento, caracteres quantitativos da carcaça, pH da carne e resultado econômico. Revista Brasileira de Zootecnia, v.30, n.3, p.844-848, 2001.

SOLOMON, M.B.; LYNCH, G.P.; NOTON, S. et al. Influence of repressed meal, whole rapeseed and soybean meal on fatty acid composition and cholesterol content of muscle and adipose tissue from ram lambs. Journal of Animal Science, v.69, p.4055-4061, 1991.

VELASCO, S.; CAÑEQUE, V.; PÉREZ, S. et al. Fatty acid composition of adipose depots of suckling lambs raised under different production sytems. Meat Science, v.59, p.325-333, 2001.

VILLAS BÔAS, A.S.; ARRIGONI, M.B.; SILVEIRA, A.C. et al. Idade à desmama e manejo alimentar na produção de cordeiros superprecoces. Revista Brasileira de Zootecnia, v.32, n.6, p.1969-1980, 2003 (supl. 2).

WOOD, J.D.; RICHARDSON, G.R.; NUTE, G.R. et al. Effect of fatty acids on meat quality: a review. Meat Science, v.66, p.21-32, 2003.

YAMAMOTO, S.M. Desempenho e características da carcaça e da carne de cordeiros terminados em confinamento com dietas contendo silagens de resíduos de peixes. Jaboticabal: Universidade Estadual Paulista, 2006. 95p. Tese (Doutorado em Zootecnia) - Universidade Estadual Paulista, 2006. 